\title{
Model of Empathic Communication for Final Year Students Suffering Anxiety from Final Assignment During Covid-19 Pandemic
}

\author{
Dini Safitri ${ }^{1}$, Dian Alfia Purwandari ${ }^{1}$, Hani Yuniani ${ }^{1}$, Dania Siregar ${ }^{1}$ \\ \{dinisafitri@unj.ac.id ${ }^{1}$,dian-alfia@unj.ac.id², hani.hun@bsi.ac.id³, siregardania@yahoo.com \\ Universitas Negeri Jakarta, Indonesia ${ }^{1234}$
}

\begin{abstract}
Many students are under pressure when working on their final project and it leads to anxiety. Especially in the time of covid-19 pandemic, many students who are working on their final task are facing numerous pressures, and a solution is immediately needed to solve their anxiousness. The purpose of this research is to develop a model of empathic communication in final year diploma (D3) and undergraduate (S1) students who are doing final assignments. This study used qualitative methodology. The result of this study is a model of empathic communication in final year students who experience anxiety while finishing their final assignment. The model has four elements: supervision with the empathic communication, time and privacy, the availability of reference for the assignment, and appreciation. These four elements can support students to be able to get out of the stress faced while working on the final task. They feel the four elements in the empathy communication model, they need when doing the final task.
\end{abstract}

Keywords: Empathic Communication; Model Development; Final year students; Anxiety; Final assignments.

\section{Introduction}

Based on research conducted by Sutjiato [1], students who experience anxiety will have a detrimental impact on their self. These detrimental effects will be seen in student's academic achievement, competence, and health. Other adverse effects are negative behaviors such as excessive smoking and drinking, and even suicide. Such anxiety, if not addressed immediately, will affect student development and brings health problems.

Another study conducted by Ramachandiran and Dhanapal [2], in the so-called gen-Y and gen- $Z$ who attended private university in Malaysia identified that the sources of academic stress for students are their studies, peer pressures, family problems, financial problems and others. They cause stress that triggers physical and psychological problems.

Stress can be experienced by anyone in any particular form, it can be in heavy, mild, longterm or short-term levels. Strees can have negative implications if they accumulate in an individual's life without the right solution. The accumulation of stress occurs as a result of an individual's inability to cope with and control his stress. According to Heiman and Kariv in Sutjiato [1], stress is a large imbalance between physical and psychological demands and the ability to respond. There is a failure to meet demand that has essential consequences. 
The causes of stress can come from the individual itself, the family, the neighborhood, the office, and the school. In this study the cause of stress came from the school. The cause of stress on students can stem from his academic life, especially from external demands and his own expectations [3].

External demands that cause students anxiety, according to Heiman and Kariv in Sutjiato [1], can stem from college assignments, schoolwork loads, parental demands, and social adjustments in their campus environment. The burden of study, including external demands that put stress on many students, correlates with the competency of lecturers resulting in the increasing complexity and difficulties of study materials.

Anxiety that students are unable to control and overcome will have a negative impact on students' cognitive, physiological, and behavioral abilities. Negative impact on cognitive abilities can be observed in the form of difficulties to concentrate, difficulties to remember learning subject, and difficulties to comprehend learning subject. Negative impact on emotional abilities can take form as difficulties of motivating themselves, the appearance anxiety, sadness, anger, frustration, and other negative effects. Physiological negative impact forms include health disorders, decreased endurance, frequent dizziness, lethargy, weakness, and insomnia. Forms of behavioral impact include procrastinating on completion of college assignments, laziness, drug and alcohol abuse, and engaging in excessive and high-risk pleasure-seeking activities [4].

According to Hadiwidjaja [5], a very different pattern of lecturer and student relationships in universities when compared to teacher and student relationships in elementary and secondary school, can also be a cause of stress for students. Lecturers rarely conduct personal dialogue with students due to large number of students in one class. The negative interpersonal relationship between lecturers and students becomes a source of stress for students. The lack of good communication between the two parties makes the interpersonal relationship of lecturers and students negative. Through a good communication process, it can meet the curiosity, needs of self-actualization, needs to convey ideas, thoughts, knowledge, and information reciprocally, and determinants of mental health.

The good relationship between students and lecturers, aims to help students in solving the problems faced, at the time of study. The intertwined relationship between students and lecturers, plays an important role in helping students in lectures. Such good relationships also play a role in decision-making by students over problems faced in college.

The effectiveness of interpersonal relationships can be achieved, if students and lecturers have something in common in interpreting the meaning of the message conveyed in the communication process. Conversely, when communication is ineffective, it can cause tense feelings so that there is a dispute between students and lecturers. This makes the interpersonal relationship of students less harmonious, resulting in stress in students. One source of stress in students, is the disagreement with lecturers. Based on these aspects, the student's interpersonal relationship with the lecturer, related to the stress experienced by the student.

For that, lecturers as educators, must have a sense of empathy. Empathy is the mental state of a person, who can feel the same circumstances, as others feel. According to Ayriza in Gamayanti [6], empathy is an aspect of social prowess that contains three main indicators, tolerance, caring for others, and understanding. Including empathy is not mocking the work of others, comforting others who are grieving, appreciating the excesses of others, forgiving the guilty, listening and not imposing will.

One of the requirements to graduate for students is to complete the final assignment or thesis. The work of final assignments or thesis often makes students depressed. The burden of this course is indeed greater, compared to other courses. Therefore, many students are under 
pressure while the student is working on the final assignment. One of the effects is stress. Students who are working on the final task and experiencing stress, should immediately find a solution to handle it. This was done, so that the stress he experienced, did not prevent him from completing the final task on time. Therefore, this research wants to develop a model of empathy communication in final-level students who are stressed on the final task work.

Not a few students are threatened with drop-out sanctions for not completing their study load with a set time. Based on research conducted by Fadillah, A. E. R. [7], at Mulawarman University, 823 students are threatened with being dropped out, because they have not completed their studies, even though the study period is coming to an end. The phenomenon of students being threatened with drop out is also found at Hasanuddin University, there are 370 students who will be dropped out because they have not finished their studies. And this is also the case at UNJ. Based on the research data, there are many students who are unable to complete their studies ideally. Some of them are threatened with dropouts. One of the reasons students are unable to complete their studies, is being unable to complete thesis or final assignments.

Thesis is a scientific essay that on some campuses, must be written by students as a condition of the end of academic education. In the process of drafting the thesis, students will pour the fruit of their minds based on the lectures that have been done into the form of scientific writing. Based on Gamayanti et al researchers [6], many students experience obstacles in compiling thesis, due to many who are unable to write research and scientific work, complicated thesis work processes, difficulty communicating with guidance lecturers, systemic problems in working on thesis, and inability to manage time. Gamayanti et al [6] research found factors that influence students during the thesis process.

Nurhindazah et al [8] also conducted research that found the obstacles faced by students in the process of completing the thesis, can have a negative impact on students. These impacts appear to be negative feelings that arise while working on the thesis. These feelings include the onset of tension, anxiety, stress, frustration, inferiority, and loss of motivation. The squeeze caused students to delay the preparation of the thesis, some even decided not to complete the thesis.

One of the things that can help students to deal with these negative feelings is the social support in the form of empathy. Such social support will result in reduced anxiety, depression, general disorders, and symptoms of body disorders. Social support can be obtained from family, peers, group members, instistusi, and the environment. To provide social support, one must have basic elements of empathy. First, imagination. This imagination is important for self-reasoning as others. Second, there is self-awareness. This awareness is a positive view of one's self and acceptance of self-advantage and deprivation. Third, there is awareness of others. This awareness is the recognition and attention of others, and acceptance of the advantages and disadvantages of others. Fourth, the absence of feelings, desires, ideas, and representations of good action results in others. Fifth, The availability of an aesthetic frame of thought [9].

According to Musfiroh [10], the empathy skills that lecturers must have include emphaty fundamentals, profound emphaty, and functional emphaty. Emphaty fundamentals show, understanding and attitudes that are accepting and open, paying attention, hearing, caring, being positive, affirmative approach, and showing enthusiasm. Second, the ability to exchange the meanings of communication through facial expressions, body language and motion, height and distance, and low height of sound.

Profound emphaty shows the breadth of lecturers' empathy in learning activities. Develop positive emotions and interactions in the form of pleasant, happy, relaxing, humorous, loving, loving, showing kindness, masking negative emotions, giving time, focusing, physical contact, relaxing, fast behaving, and informal climate. Functional emphaty is a direct function in the 
learning process of teaching, namely empathy of class groups, building perspective on others in a group by jointly organizing the perspective by using circular settings, patterns, and codes, performing control, discipline, honesty of manners and empathic structure. Third, a mental grouping based on the ability to combine a variety of child typologies, cultural differences, pursuing different groups, and gender differences in one mental situation that empathizes with each other, cares, and respects each other.

The formulation of the problem in this study is two. First, how is the empathy communication model in late-level students who are stressed out in the final assignments of D3 and S1 students? Second, how is the development of empathy communication in final-level students who are stressed out in the final assignments of D3 and S1 students?

The purpose of this research is also two. First, create a model of empathy communication in final-level students who are stressed out in the final assignments of D3 and S1 students. Second, to develop empathy communication in final-level students who are stressed on the final assignments of D3 and S1 students

The findings targeted in this study are a model of empathy communication in final-level students who experience stress in the work of the final task can be explained in the thesis course or the final task of the student's scientific work so as to support the development and development of technological and socio-cultural sciences.

\section{Method}

The research method used in this study is qualitative methodology. According to Wahab [11], qualitative research is research that examines the quality of relationships, activities, situations, or various materials. Qualitative research emphasizes holistic descriptiveness, which explains in detail the ongoing activities or situations than comparing the effects of certain treatments. Qualitative research also seeks to shed light on people's attitudes or behaviors per person.

Qualitative research emphasizes meaning and bound values, to understand social interactions, develop theories, ensure data correctness, and research developmental history. Therefore, qualitative researchers should have the ability and courage, always maintain networking, have a great curiosity and be open minded.

Qualitative research is a study aimed at understanding social reality. This research wants to see the world from what it is, not the world it should be. So qualitative researchers are researchers who have open minded properties. Researchers are key instruments. Therefore, researchers must have a wide range of theories and insights in order to analyze, and construct more clearly researched objects.

Qualitative research is usually descriptive, and emphasizes processes more than results, and tends to analyze its data in an inductive way. This type of research is descriptive. Research sites are located in two places, namely at Universitas Negeri Jakarta and Univeritas Andalas. The focus of the research is on D3 and undergraduate students who are working on the final task. The research measures in the cauldron research start from identifying the phenomenon to be studied, conducting data analysis, identifying participants in the study, developing analysis, collecting data, and formulating conclusions. 


\section{Results and Discussion}

To create a model of empathy communication in final year students who experience anxiety on the final assignments of D3 and Undergraduate students, researchers have conducted interviews and documentation studies to research informants. Based on the interview, the findings found that the stress that informants experience makes them panic and anxious, so it is a burden on their minds. Here is one of the informant's statements, Arnita (Unand Pharmacy Undergraduate student):

"I'm so panicked and anxious, the mind goes on and like if I take a break or pause from doing thesis, it feels like it's not calm because it feels like something hasn't been done yet, so sometimes I'm not in the mood to do anything."

This is due to the influence of hormones. When a person feels stress, there is a process in the body that causes stress caused by three types of hormones. First, adrenaline hormones. Both hormones are norepinephrine. Third, the hormone cortisol. These three hormones decide on reactions when stressed. In Arnita's case, she became unmotivated from doing anything. Such hormones can suppress the immune system, increase blood pressure and blood sugar, causing acne, obesity and others. In addition to panic and anxiety, many students are also experiencing a bit of trauma. They become worried when they want to make a decision. Here is one of the informant's statements, Willyandi (D3 Student Public Relations UNJ):

"I'm afraid (that) I'm wrong, if I want to make my own decisions or initiatives, even if it's about my final assignment. So if I want to do anything, I ask my friend, 2 or 3 people, so I feel confident."

The biggest factor that causes students stress comes from supervisor. A lot of un-emphatic communication coming from supervisor. Revisions including change of title, while the final task process is halfway through, are factors that make the emphatic communication between the student and the supervisor impossible. Here is an excerpt from one of the informant's statement: "Often some time when consulting with my supervisor, my work is revised, and I had to change the title, when it's already chapter two. When I asked how to work on the next chapter, he said just do it first, figure out how yourself. I tried to find and follow previous research but in fact it was wrong, so I became worried a lot."

As a result of the already severe stress of working on the thesis, many students don't show themselves again for the supervising process, they even withdrawing from their social circle. When a friend asked him about it, he refused to talk about his thesis. In the end, many of them chose to drop out, or continuing their studies at other universities. During the covid-19 pandemic, the stress is increasing due to the various restriction put of the situation. They can't move freely to do data gathering and the infrastructure they have is also less supportive. As Choirunnisa experienced, her thesis progressed slowly, and she worked on the thesis depending on free wi-fi at the school where she researched.

The average informant is a UNJ student, the majority of them make schools as research site. During this covid-19 pandemic, school activities took place online, thus affecting the progress of thesis. In addition, students who experience stress, during the covid-19 pandemic, also experience more laziness. There are also others who do other non-thesis activities, like teaching or working to finance life in Jakarta. This was because the family's condition required him to work. In addition, they also feel stressed while working on the thesis. 
The stress is due to communication problems with lecturers. These communication problems arose because their research methods were considered problematic, and the findings of the study were perceived to be lacking in validation of instruments or media experts. This situation created anxiety and resulting in laziness. Some of informants already finish their exam and defense, but then had a problem unrelated to the thesis process, which then affects the grade of their thesis. And that is enough to stress the student [12].

Many of the students who experienced stress while working on the final task, have been stressed since the initial discussion with their supervisor. The students who did the final task during the covid-19 pandemic feel more stressed. In this covid-19 pandemic, students doing their assignment with more relaxed atmosphere at home. Nevertheless, there is still a particular time where they have online discussions with lecturers and were given a deadline. The deadline makes students feel quite stressed since they think that one-week deadline is too short.

Students said the way they relieve stress is to seek distraction into hobbies. Their hobby mostly is watching movies and reading novels. When this distraction didn't work, they mostly went to a friend to have a conversation. This conversation aimed only to channel their needs to be listened to. Their conversation mostly consists of daily experience. This communication model is felt to be effective enough to relieve stress in working on thesis. Here's one excerpt from the source's statement:

"Because there are friends who I can talk to and gave me advice even if it is just something like 'just take a break, and when you have cooled off start working on your task again' or 'remember your motivation when you start college'".

The presence of friends who can help during the process of the thesis is considered helpful, as much as helpful as lecturers who can communicate with empathy to the student. Here's a model of empathy communication we developed based on the findings above:

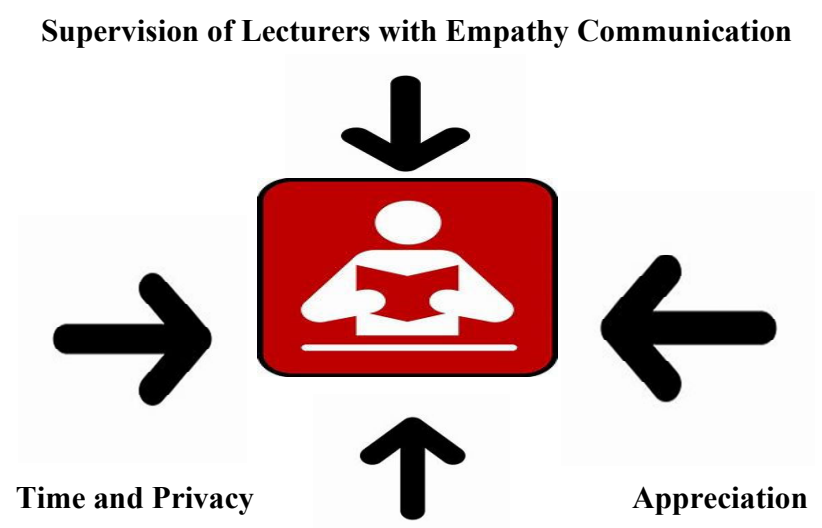

Reference to Support Final Task Writing

Fig. 1. Empathy Communication Model in Final Year Students Who Experience Stress During Final Task Work 
The presence of lecturers who provide direction and supervision with empathy communication is key to this model. In addition, students who are stressed while working on thesis or final assignment also need to get time and privacy in working on the thesis from their environment, as well as the availability of reference resources to support the writing of the final task. Another important factor is the appreciation of his or her friends while working on the thesis. Thus, the model of empathy communication in final year students who experience stress during the work of the final task has four elements, namely: 1) Supervision of the lecturer with empathic communication, 2) Time and Privacy, 3) Reference resources to support the writing of the final task, 4) Appreciation.

There are lecturers supervising the progress of the final task with empathy communication is an important factor that can encourage students to be able to complete the final task. Such empathy communication can take in the form of giving time and privacy to students to work on research in accordance with the research roadmap that students and supervisors have drawn up at the beginning of the process. In addition, support from the campus in providing a reference resource to support the writing of the final task, also felt very helpful. And finally, no matter how little progress is made, with the appreciation, will motivate students to complete the final task.

\section{Conclusion}

The model of empathy communication in final-year students who experience anxiety during final assignment work is a model created to help final students to complete their thesis on time. The student had to be helped because of stress and anxiety they experienced in the process of working on their thesis. This help is needed to save them from becoming college dropouts, something that is both unwanted and unnecessary. To relieve stress on the final year students, there are four necessary elements: 1) Supervision of the lecturer with empathic communication, 2) Time and Privacy, 3) Reference resource to support the writing of the final assignment, 4) Appreciation. The four elements described had to be offered for final-year students, so that they can complete their thesis and pass their exam and defense. The four elements in this empathy communication model are elements that interact with each other, concerted efforts are required to maximize the result of empathy communication model to help final year student on their final assignment.

\section{References}

[1] M. Sutjiato, G. D. Kandou, and A. A. T. Tucunan, "Relationship of Internal and External Factors with Stress Level in Students of Faculty of Medicine, Sam Ratulangi University Manado (In Bahasa)," JIKMU, vol. 5, no. 1, pp. 30-42, 2015.

[2] M. Ramachandiran and S. Dhanapal, "Academic Stress Among University Students: A Quantitative Study of Generation Y and Z's Perception," Pertanika J. Soc. Sci. Hum, vol. 26, no. 3, pp. 2115-2128, 2018.

[3] H. Bayne, "Training Medical Students in Empathic Communication," J. Spec. Gr. Work, vol. 36, no. 4, pp. 316-329, 2011.

[4] E. Septiani, "The relationship between stress levels and humor in college students (In Bahasa)," UIN SGD, 2013.

[5] S. Hadiwijaya, "Thought of KBK Implementation in Faculty of Medicine (In Bahasa)," GASTER, 
vol. 8 , no. 2 , pp. 721-730, 2011 .

[6] Gamayanti, Witrin, Mahardika, and I. Syafei, "Self Disclosure and Stress Levels in Students Working on Thesis (In Bahasa)," PSYMPATHIC J. Ilm. Psikol., vol. 5, no. 1, pp. 115-130, 2018.

[7] A. E. R. Fadillah, "Stress and motivation to study in psychology students of Mulawarman University who are preparing the thesis (In Bahasa)," Ejournal Psikol. Univ. Mulawarman, vol. I, no. 3, 2013.

[8] D. Nurhindazah and E. R. Kustanti, "The Relationship Between Parental Social Support And Adversity Intelligence In Students Who Undergo Final Assignment Courses At the Faculty of Engineering Diponegoro University (In Bahasa),” J. Empati, vol. 5, no. 4, pp. 645-652, 2016.

[9] S. Iswati, "Stress Level Identification Tool for Students Working on Final/Thesis Tasks (In Bahasa)," J. Inform. UPGRIS, vol. 4, no. 1, pp. 56-63, 2018.

[10] M. Tadkiroatun, "Show and Tell Educative For Empathy Development, Affiliate-Conflict Resolution, and Positive Habits of Early Childhood (In Bahasa)," J. Kependidikan, vol. 41, no. 2, pp. 129-143, 2011.

[11] S. N. A. Wahab, M. N. Izna, M. F. Khamidi, and N. Jamaluddin, "Qualitative Assessment of Mould Growth for Higher Education Library Building in Malaysia," in Procedia Social and Behavioral Sciences, 2015, pp. 252-261.

[12] S. Meyers, K. Rowell, M. Wells, and B. C. Smith, "Teacher Empathy: A Model of Empathy for Teaching for Student Success," Coll. Teach., vol. 67, no. 3, pp. 160-168, 2019, doi: 10.1080/87567555.2019.1579699. 